\title{
Health related quality of life and treatment satisfaction in diabetes mellitus patients attending a tertiary care centre in the north eastern part of India
}

\author{
M. Bijoy ${ }^{1}$, Sourav Misra ${ }^{2}$, Laishram Chittaranjan Singh ${ }^{3 *}$, Roshlin Keisham ${ }^{4}$, \\ Sandipa Roy Chowdhury ${ }^{5}$, Dipendra Oli ${ }^{6}$ \\ ${ }^{1}$ Assistant Professor, Department of Medicine, Regional Institute of Medical Sciences, Imphal, Manipur, INDIA. \\ 3,5,6PGTs Department of Medicine, Regional Institute of Medical Sciences, Imphal, Manipur, INDIA. \\ 2,4Senior Residents Department of Medicine, Regional Institute of Medical Sciences, Imphal, Manipur, INDIA. \\ Department of Medicine, Regional Institute of Medical Sciences, Imphal, Manipur, INDIA. \\ Email: crlaishram@gmail.com
}

\section{$\underline{\text { Abstract }}$}

\begin{abstract}
Background: Diabetes mellitus is a chronic illness requiring continuous medical care and patient self-management education. The quality of life in diabetes is reduced and its daily treatment need, acute and chronic complications have great impact on physical, psychological and social well-being of diabetic patients. The study was conducted to find out the health related quality of life (HRQOL) using the WHO (FIVE) Well Being Questionnaire and different factors affecting it along with treatment satisfaction using the Modified Diabetes Treatment Satisfaction Questionnaire (DTSQ) in the patients. Materials and methods: The study was an observational analytical study done in the department of General Medicine, RIMS Imphal Results: Out of 430 diabetes mellitus patients males and females were respectively 229 and 201. The mean age of the patients was 53.34 years with a standard deviation of 15.70 years. It was found that the health related quality of life deteriorates with increase in age and longer duration of diabetes is related to worse quality of life. Females have better quality of life. Surprisingly, BMI has no relation with the health related quality of life. Increase in both systolic and diastolic blood pressure, poor glycaemic control, dyslipidemia, renal impairment, diabetic retinopathy and increase in number of complications are found to have significant negative impact on the health related quality of life.

Key Words: Diabetes, Quality of life, treatment satisfaction.
\end{abstract}

*Address for Correspondence:

Dr. Laishram Chittaranjan Singh, Department of Medicine, Regional Institute of Medical Sciences, Imphal, Manipur, INDIA.

Email: crlaishram@gmail.com

Received Date: 02/04/2020 Revised Date: 24/05/2020 Accepted Date: 17/07/2020

DOI: https://doi.org/10.26611/10211625

This work is licensed under a Creative Commons Attribution-NonCommercial 4.0 International License. $(\boldsymbol{c c})$ EY-NC

\begin{tabular}{|l|l|}
\hline \multicolumn{2}{|c|}{ Access this article online } \\
\hline Quick Response Code: & Website: \\
\hline & www.medpulse.in \\
& \\
\hline
\end{tabular}

\section{INTRODUCTION}

Diabetes is now one of the most common noncommunicable diseases globally. It is the fourth or fifth leading cause of death in most high-income countries and there is substantial evidence that it is epidemic in many low and middle income countries like India. It is now recognized that it is the developing countries that presently face the greatest burden of diabetes. Diabetes Mellitus is defined as fasting blood glucose is equal to or more than $126 \mathrm{mg} / \mathrm{dl}$ and/or 2 hours post prandial blood glucose is equal to or more than $200 \mathrm{mg} / \mathrm{dl}^{1}$ The quality of life in diabetes is reduced and it was found that emotional coping with the diagnosis, daily treatment need and acute and chronic complications had great impact on physical, 
psychological and social well-being of diabetic patients. ${ }^{2}$ Very few data is available from this part of country on all these aspects of Diabetes Mellitus. This study aims to find out health related quality of life (HRQOL) using the WHO (FIVE) Well Being Questionnaire and different factors affecting it along with treatment satisfaction using the Modified Diabetes Treatment Satisfaction Questionnaire (DTSQ) in the patients and if there is any correlation or not between HRQOL and treatment satisfaction in Diabetes Mellitus.

\section{MATERIALS AND METHODS}

The study was conducted in the Department of General Medicine (Including Endocrinology Clinic and Medicine Ward) of Regional Institute of Medical Sciences, Imphal, Manipur, India for a period of two years starting from September 2016. It was an observational analytical study which included both type 1 and type 2 diabetes mellitus above the age of 18 years. All secondary diabetes mellitus, gestational diabetes mellitus, patients with other associated endocrinopathies or chronic illnesses not as consequences of diabetes mellitus, which might affect the quality of life on their own Prediabetes/Impaired glucose tolerance were excluded from the study. Health related quality of life was assessed by the standard WHO (five) Well-being Index Questionnaire 3 and, Treatment satisfaction was assessed by the standard Diabetes Treatment Satisfaction Questionnaire. $^{4}$

\section{RESULTS AND OBSERVATION}

There are 229 males and 201 females in the present primary sample of 430 diabetes mellitus patients with respective percentage of 53.26 and 46.74 .

\begin{tabular}{ccc} 
Table 1: Demographic data of the patients divided into different groups \\
\hline Characteristics & Groups & Number(\%) \\
\hline Sex & Male & $221(53.26)$ \\
& Female & $201(46.74)$ \\
Age & $18-34$ & $63(14.66)$ \\
& $35-44$ & $69(16.05)$ \\
& $45-54$ & $82(19.07)$ \\
Bears) & $55-64$ & $100(23.26)$ \\
(BMI) & $>65$ & $116(26.98)$ \\
(kg/m2) & $<18.5$ & $0(0.00)$ \\
& $18.5-22.9$ & $20(17.21)$ \\
& $23-24.9$ & $74(17.21)$ \\
Duration of diabetes & $25-29.9$ & $325(75.58)$ \\
(months) & $\geq 30$ & $11(2.56)$ \\
& $<60$ & $163(37.91)$ \\
Systolic Blood Pressure (SBP) & $\leq 130$ & $126(29.30)$ \\
(mmHg) & $131-140$ & $86(20.00)$ \\
& $>140$ & $218(50.70)$ \\
Diastolic blood pressure & $\leq 85$ & $173(40.23)$ \\
& $86-90$ & $165(38.37)$ \\
& $>90$ & $92(21.40)$ \\
\hline
\end{tabular}

Statistical analysis Worksheet and then to SPSS (Statistical Package for Social Sciences) Data Document. Then after thorough scrutiny and checking of the data, statistical analysis was performed by using IBM: SPSS Statistics Version 21 and MINITAB Release 11.12, 32 Bit. Numerical/continuous variables that follow normality and equality of variances are presented as Mean \pm SD (standard deviation) and qualitative/categorical variables are again described as number of cases and percentages. The means of all numerical data like age, BP, BMI, duration of diabetes mellitus, and all biochemical findings are compared separately among the three categories of well-being status of the patients by ANOVA, commonly known as F-test. For categorical variables, like gender and fundus examination are exhibited in terms of number of cases along with percentages and subsequently Chi square-test or Fisher's exact test (in case theoretical cell frequency is $<5$ ) is applied to establish the relationship. The tests are adopted separately for wellbeing status (with all the variables) as well as for diabetes treatment satisfaction (with age and gender) of the patients. Finally Karl Pearson Coefficient of Correlation " $r$ " is also used to find degree of relationship between scores of earned from the WHO Five Well Being Questionnaire and from the Diabetes Treatment Satisfaction Questionnaire.
The information was first transferred to Microsoft Excel

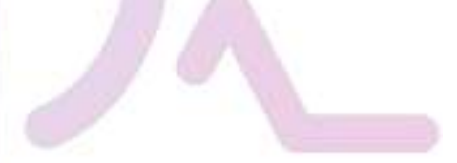


Table 2: Distribution of mean \pm SD of age and sex according to wellbeing status of patients

\begin{tabular}{cccccc}
\hline Wellbeing status & $\mathbf{N}$ & Mean \pm SD & Male & female & p-value \\
\hline Age & $\begin{array}{c}\text { Good mood } \\
\text { (yr) }\end{array}$ & 230 & $45.57 \pm 13.15$ & $107(46.7 \%)$ & $<0.001$ \\
& $\begin{array}{c}\text { Low } \\
\text { Dood }\end{array}$ & 193 & $62.00 \pm 13.56$ & $118(51.5 \%)$ & \\
& & 7 & $70.00 \pm 9.93$ & $4(1.7 \%)$ & \\
\hline
\end{tabular}

Table 3: Distribution of mean \pm SD of SBP, DBP, BMI, duration of diabetes and serum creatinine according to the well-being status of the patient

\begin{tabular}{ccccc}
\multicolumn{5}{c}{ patient } \\
\hline Well being status & $\mathrm{N}$ & Mean \pm SD & P value \\
\hline SBP & Good mood & 230 & $138.56 \pm 13.79$ & $<0.001$ \\
& Low mood & 197 & $149.92 \pm 17.72$ & \\
DBP & Depression & 7 & $154.86 \pm 15.00$ & \\
& Good mood & 230 & $85.07 \pm 6.32$ & $<0.001$ \\
& Low mood & 193 & $88.81 \pm 8.25$ & \\
BMI & Depression & 7 & $88.57 \pm 3.95$ & \\
& Good mood & 230 & $26.25 \pm 2.04$ & 0.176 \\
& Low mood & 197 & $25.98 \pm 1.81$ & \\
Duration & Depression & 7 & $25.25 \pm 1.60$ & \\
Of & Good mood & 230 & $84.54 \pm 78.27$ & $<0.001$ \\
Diabetes & Dow mood & 193 & $174.75 \pm 134.93$ & \\
mellitus & Depression & 7 & $337.71 \pm 140.70$ & \\
Serum & Good mood & 230 & $1.17 \pm 75$ & $<0.001$ \\
Creatinine & Low mood & 193 & $2.90 \pm 1.96$ & \\
& Depression & 7 & $5.16 \pm 2.44$ & \\
\hline
\end{tabular}

Table 4: Distribution of mean \pm SD of age and sex according to diabetes treatment satisfaction of patients

\begin{tabular}{ccccccc}
\hline & $\begin{array}{c}\text { Diabetes } \\
\text { treatment } \\
\text { Satisfaction }\end{array}$ & N & Mean \pm SD & Male & female & p-value \\
\hline Age & $\begin{array}{c}\text { completely } \\
\text { (yr) }\end{array}$ & 213 & $45.03 \pm 12.26$ & $99(43.2 \%)$ & $114(49.5 \%)$ & $<0.001$ \\
& $\begin{array}{c}\text { satisfied } \\
\text { Fairly } \\
\text { satisfied } \\
\text { Unsatisfied }\end{array}$ & 204 & $60.96 \pm 14.66$ & $123(53.7 \%)$ & $81(40.3 \%)$ & \\
\hline
\end{tabular}

Table 5: Distribution of Well-being status and diabetes treatment satisfaction

\begin{tabular}{|c|c|c|c|c|}
\hline \multirow[t]{2}{*}{ Well being status } & \multicolumn{3}{|c|}{ Diabetes treatment satisfaction } & \multirow{3}{*}{$\begin{array}{c}\text { P- } \\
\text { value }\end{array}$} \\
\hline & $\begin{array}{c}\text { Completely } \\
\text { satisfied }\end{array}$ & $\begin{array}{c}\text { Fairly } \\
\text { satisfied }\end{array}$ & Unsatisfied & \\
\hline Good mood & $193(83.9 \%)$ & $\begin{array}{c}37 \\
(16.1 \%)\end{array}$ & - & \\
\hline Low mood & $20(10.4 \%)$ & $\begin{array}{c}163 \\
(84.5 \%)\end{array}$ & $10(5.2 \%)$ & \\
\hline Depression & - & $\begin{array}{c}4 \\
(57.1 \%)\end{array}$ & 3 (42.9\%) & $<0.001$ \\
\hline
\end{tabular}

\section{DISCUSSION}

In our present study primary sample size was 430 patients with diabetes mellitus out of which 229 were males and 201 were females with respective percentage of 53.3 and 46.7. Overall mean age of the patients was 53.34 years with a standard deviation of 15.70 years. Age: We have found a statistically highly significant association between the age of the patients and the well-being status, as age enhances the well-being status is found to deteriorate. Prajapati et al..20 including 250 patients using modified diabetes quality of life-17 (MDQol-17) - a disease specific quality of life assessment tool, it was found that the patients less than 40 years of age had a mean \pm SD score of $71.47 \pm 14.16$ indicating a good mood status. Similarly, age between 40 65 years and above 65 years had graded decline in the mean \pm SD scores $66.83 \pm 14.86$ and $62.38 \pm 15.16$ respectively and these had a statistically significant $p$-value of $<0.05$. It was concluded that with an increase in age the 
number of complications increases. In our study we have found that in females the percentage patients in good mood status is higher compared to the males, and the low mood status and depression are comparatively lower than those in the males. The reason for females having poorer quality of life is explained as unemployment, lower educational status, emotional attachments to various things and a sense of household and familial responsibilities. Though it is not confirmed, but reason for the opposite findings in our study can be related to geographical, racial and socioeconomic differences of this part of the country where many of the women are educated and are working outside home.

Duration of Diabetes Mellitus: In our study we have found that with the increase in the duration of diabetes the quality of life declines. A study conducted by Prajapati et $a l . .^{5}$ also showed similar result. The study used a generic quality of life assessment tool MDQol where the mean \pm SD score in duration of illness less than 1 year was $75.93 \pm 10.93$ and with duration of diabetes for more than 10 years was $63.88 \pm 14.18$, which was significantly lower with a p-value of 0.004

From various previous studies it is concluded that the longer is the duration of diabetes mellitus the more is the risk of developing complications. Along with that years of restricted lifestyle and diet modification adversely affects the quality of life. Though in some studies as mentioned above has shown only the duration of illness does not correlate with quality of life but still in most of the cases it does not hold true, as in our study.

Body Mass Index: In our study we have found that BMI has no relation with the quality of life. The study conducted by Raghavendra et al.. ${ }^{6}$ showed a similar result that BMI has no correlation with the quality of life, where the Spearman's correlation value between quality of life and BMI was found to be -0.140 with a insignificant $p$-value of $>0.05$.

Blood pressure: In our study we have found that both the systolic blood pressure and diastolic blood pressure has a statistically significant correlation with the quality of life. It is found that both SBP and DBP means are the highest in the group of patients with depression followed by low mood group and in the good mood group of patients these are the lowest. The reason for this finding can be explained based on the fact that presence of hypertension increases the risk of developing both micro and macrovascular complications which cause decline in the quality of life.

Increase in serum creatinine is a marker of significant renal impairment and thus with increase in the level of creatinine the quality of life is found to be deteriorating.

Treatment satisfaction with age: In our study we have found that with increase in age the satisfaction to treatment decreases amongst the patients. In a study conducted by Biderman et al.. ${ }^{7}$ it was found that age does not have any correlation with the treatment satisfaction which is opposite to the result of our study.

Treatment satisfaction with sex: In our present study we have found that females are comparatively more satisfied to the treatment. Around $40 \%$ of the males are completely satisfied to the treatment whereas $56.7 \%$ of the females are completely satisfied to the treatment.

Correlation between health related quality of life and treatment satisfaction: In our study we have found that there is significant correlation between quality of life and treatment satisfaction in diabetes patients. It is concluded that better well-being status corresponds better satisfaction of treatment vis-à-vis lower well-being status corresponds lesser satisfaction to treatment. In the study conducted by Saatci et al.. ${ }^{8}$ similar result was found. A significant positive correlation between WHO-22 subscales scores and DTSQ total scores was found with statistically significant $p$-value of 0.0001 .

It can be concluded the different factors affecting quality of life also affects the treatment satisfaction. Along with that the health related quality of life may be linked to treatment satisfaction due to patients' beliefs and attitudes towards taking medications. All of these contribute to the positive correlation between these two variables of our study.

\section{CONCLUSION}

In our study of 430 diabetic patients we have found that the health related quality of life deteriorates with increase in age. Females are found to have better quality of life. Longer duration of diabetes is related to worse quality of life. Body mass index is not found to have any correlation with the quality of life whereas increase in both systolic and diastolic blood pressure is found to have significant negative impact on the health related quality of life. Patients with poor control of diabetes as evidenced by elevated FBG/ PPBG/ HbAlc level as well as those with dyslipidaemia are found to have worse quality of life. Renal impairment as evidenced by elevated serum creatinine level and diabetic retinopathy are found to cause deterioration in the health related quality of life. With increase in number of complications the quality of life sharply declines. The health related quality of life has direct relation with treatment modality. Increasing number of injections is associated with deterioration of the quality of life whereas addition of more oral hypoglycaemic agents improves it.

It is also found that younger patients and females are more satisfied with the treatment and treatment satisfaction and quality of life are correlated to each other. 


\section{REFERENCES}

1. Chamberlein JJ, Rhinehart AS, Shaefer CF, Neuman A. Diagnosis and management of diabetes: synopsis of the 2016 American Diabetes Association Standards of Medical Care in Diabetes. Ann Intern Med 2016;164(8):542-52.

2. Saatci E, Tahmiscioglu G, Bozdemir N, Akpinar E, Ozcan $\mathrm{S}$, Kurdak $\mathrm{H}$. The well being and treatment satisfaction of diabetic patients in primary care. Health Qual Life Outcomes 2010;8:67.

3. Topp CW, Osteqaard CD, Sanderqaard S, Bech P. The WHO-5 Well-Being Index: a systematic review of the literature. Psychther Psychosom 2015;84(3):167-76.

4. Saisho Y. Use of diabetes treatment satisfaction questionnaire in diabetes Care: Importance of patient reported outcomes. Int $\mathrm{J}$ Environ Res Public Health 2018;15:947-54
5. Prajapati VP, Blake R, Acharya LD, Seshadri S. Assessment of quality of life in type II diabetic patients using the modified diabetes quality of life (MDQol)-17 questionnaire. Braz J Pharm Sci 2017;53(4):17-24

6. Raghavendra N, Viveki RG, Gadgade A. An observational study to assess the health-related quality of life of type 2 diabetes mellitus patients attending a tertiary care hospital, Belagavi. Int J Community Med Public Health 2017 Sep;4(9):3347-53.

7. Raghavendra N, Viveki RG, Gadgade A. An observational study to assess the health-related quality of life of type 2 diabetes mellitus patients attending a tertiary care hospital, Belagavi. Int J Community Med Public Health 2017 Sep;4(9):3347-53.

8. Saatci E, Tahmiscioglu G, Bozdemir N, Akpinar E, Ozcan $\mathrm{S}$, Kurdak H. The well being and treatment satisfaction of diabetic patients in primary care. Health Qual Life Outcomes 2010;8:67.

\section{Source of Support: None Declared Conflict of Interest: None Declared}

Policy for Articles with Open Access:

Authors who publish with MedPulse International Journal of Medicine, Print ISSN: 2550-7583, Online ISSN: 2636-4751 agree to the following terms: Authors retain copyright and grant the journal right of first publication with the work simultaneously licensed under a Creative Commons Attribution License that allows others to share the work with an acknowledgement of the work's authorship and initial publication in this journal.

Authors are permitted and encouraged to post links to their work online (e.g., in institutional repositories or on their website) prior to and during the submission process, as it can lead to productive exchanges, as well as earlier and greater citation of published work. 